scientific creativity. Wisconsin $\mathrm{Pu}-$ blications in the History of Science and Medicine, Vol. 4. (University of Wisconsin Press, Madison, Wiscon$\sin )$,

Izquierdo, M., 1988. La contribució de la teoria del flogiste a l'estructuracto de la ciència química. Implicacions didàctiques, Enseñanza de las ciencias, Vol. 6, pp. 67-74.

Lavoisicr, A.L., 1789 (1965). Traité Elémentaire de Chimie. 2 tomos. (Éditions Culture et Civilisation:
Bruselas), (Éditions Jacques Gabay, Sceaux, dos tomos en un volumen). Tratado Elemental de Quimica. Traducido por Ramón Gago, 1982, dos tomos en un volumen (Alfaguara, Madrid). Tractat Elemental de Química. Traducido por Miquel Baltà y Florenci Coma, 1919 (1989), un volumen, (Institut d'Estudis Catalans, Barcelona).

Mckie, D., 1952 (1990). Antoine Lavoisier, scientist, economist, social reformer. (Da Capo Press: New York).
Poirier, J.P., 1993. Antoine Laurent de Lavoisier 1734-1794. París.

Porteła, E. y Soler, A., 1990. Penetración y difusión de la química moderna en España en J. Fernández y I. González Tascón (Eds) Ciencia, Técnica y Estado en la España ilustrada. (MFC: Madrid).

Scheler, L., 1966. Lavoisier et le principe chimique. (Seghers: París).

\title{
PRESENTACIÓN DE REVISTAS
}

DIDASKALIA.

RECHERCHES SUR LA COMMU. NICATION ET L'APPRENTISSAGE DES SCYENCES ET DES TECHNIQUES

Editada por el INRP (Institut National de Recherche Pedagogique) francés y la Université Laval (Canadá), acaba de aparecer el primer número de esta revista que pretende «contribuir al desarrollo de la investigación didáctica, permitiendo la difusión en lengua francesa de investigaciones $e$ innovaciones".

La revista, que publicará tres números por año, se estructura en cinco secciones: editorial, artículos de investigación, punto de vista, comptes rendus de innovaciones y notas de lectura.

Las personas interesadas pueden dirigirse a:

\section{Didaskalia}

INRP publications

29 rue d'Ulm

75230 Paris, Cedex 05. Francia

Fax: 33 I 4354320 I

\section{REVISTA ESPAÑOLA DE FÍSICA}

La Revista Española de Física, una publicación de la Real Sociedad Española de Física que se publica desde 1987 , inicia actualmente una nueva etapa con novedades en su presentación y contenido, intentando llegar a sectores más amplios. Junto con informaciones sobre la vida de la Física en el mundo y en España, artículos sobre nuevas ideas o problemas importantes y entrevistas con físicos prominentes, incluye una sección de Enseñanza en la que colaborarán habitualmente profesores de Bachillerato y COU. 